\title{
The Effect of Mangosteen (Garcinia mangostana), Cinnamon (Cinnamomum verum) and Chilli (Capsicum annum) Extracts in Minimizing Autoxidation of Sesame (Sesamum indicum) Oil
}

\author{
Umani Walallawita $^{1}$, Dilini Bopitiya ${ }^{2}$, Subajiny Sivakanthan $^{3}$, Isuri Jayawardana ${ }^{4}$, \\ Terrence Madhujith ${ }^{5}$ \\ ${ }^{1}$ Department of Applied Nutrition, Wayamba University of Sri Lanka, Kuliyapitiya, Sri Lanka, \\ ${ }^{2}$ University College of Ratmalana, University of Vocational Technology, Ratmalana, Sri Lanka \\ ${ }^{3}$ Department of Agricultural Chemistry, Faculty of Agriculture, University of Jaffna, Jaffna, Sri Lanka \\ ${ }^{4}$ Department of Agricultural Systems, Faculty of Agriculture, Rajarata University of Sri Lanka, Puliyankulama, \\ Sri Lanka \\ ${ }^{5}$ Department of Food Science and Technology, Faculty of Agriculture, University of Peradeniya, Peradeniya, \\ Sri Lanka
}

Corresponding Author Email: ${ }^{1}$ umanishanika@gmail.com , ${ }^{3}$ suba106@gmail.com

\begin{abstract}
During the past two decades, the use of natural plant extracts as antioxidants in edible oils is becoming popular to prevent the use of synthetic antioxidants. This study was carried out to study the effect of three natural plant extracts; mangosteen (Garcinia mangostana) peel, cinnamon (Cinnamomum verum) and chilli (Capsicum annum) extracts on autoxidation of sesame (Sesamum indicum) oil. Dried powder ( $20 \mathrm{~g}$ ) of each plant was mixed with $30 \mathrm{ml}$ of acetone, stirred for $30 \mathrm{~min}$ at room temperature and filtered and the solvent was removed by rotatory evaporator to get plant extracts. Sesame oil was heated to $60{ }^{\circ} \mathrm{C}$ and plant extract was added at $5 \mathrm{mg}$ per $100 \mathrm{mg}$ of sample while stirring. Just after adding plant extracts, oil samples $(5 \mathrm{~mL})$ was taken into glass vials, flushed with nitrogen and closed with caps to assess the oxidative stability by accelerated oven storage test (at $65 \pm 5{ }^{\circ} \mathrm{C}$ for up to 28 days). Samples were drawn on 1, 3, 5, 7, 14, 21 and 28 days and analyzed for chemical parameters such as peroxide value (PV), thiobarbituric acid reactive substance (TBARS) assay and specific absorptivity of conjugated dienes (CDs) and conjugated trienes (CTs). All samples treated with plant extracts showed increased stability against autoxidation than control. The samples treated with mangosteen peel showed significantly $(\mathrm{p}<0.05)$ lower rate of percent increment of PV, CDs, TBARS and CT $(2.76,0.84,0.12$ and $1.14 \%$, respectively) than the samples treated with other extracts. The samples treated with cinnamon showed significantly $(\mathrm{p}<0.05)$ higher percent increment of PV and CTs (3.18 and 1.97\%, respectively) than the samples treated with chilli extract (2.99 and $1.42 \%$, respectively) while CDs and TBARS values of samples treated with cinnamon extract were significantly $(\mathrm{p}<0.05)$ lower than the samples treated with chilli extracts. Therefore it is concluded that all three plant extracts can act to reduce the autoxidation of sesame oil, however, the mangosteen peel extract is the most effective to reduce the autoxidation of sesame oil. Thus, mangosteen peel, a waste product, could be effectively used at low cost to increase the stability of sesame oil against autoxidation.
\end{abstract}

Keywords: oxidative stability, sesame oil, natural plant extracts, autoxidation

\section{Introduction}

Use of natural plant derived sources as antioxidants in fats and oils is an emerging trend. Oxidation of oil destroys essential fatty acids and produces low molecular weight off flavor compounds and other toxic compounds which make the oil less acceptable or unacceptable for consumption. The unsaturated fatty acids 
present in the oil can undergo autoxidation easily because the hydrogen atom adjacent to the double bond can be removed easily to produce free radicals which then undergo chain reaction (Choe and Min, 2006). Thus, incorporation of some antioxidants could retard the autoxidation reaction. The growing interest in the replacement of synthetic food antioxidants by natural ones has led the focus on inexpensive natural sources (Suttirak and Manurakchinakorn, 2014).

Sesame is an ancient and most important oil crop cultivated in the world. Sesame plays an important role in human nutrition and medicinal and pharmaceutical uses. About $65 \%$ of annual sesame crop planted is processed into oil. Sesame seed contains high content of oil (50\%). Sesame oil contains oleic (35-50\%), linoleic (35-50\%), palmitic (7-12\%) and stearic (3.5-6\%) acids. Sesame oil has superior oxidative stability compared with most other vegetable oils during processing and storage. This stability could be attributed to endogenous antioxidants namely lignans (sesamin and sesamolin) and tocopherols (mainly $\gamma$-tocopherol) (Kamal-Eldin and Appelqvist, 1995). Since sesame oil contains unsaturated fatty acids which can undergo autoxidation, incorporation of antioxidants could reduce the autoxidation. Studies on effect of natural plant extracts on autoxidation of sesame oils are limited.

Therefore in this study, effect of three natural plant extracts mangosteen peel, cinnamon and chilli, which are known antioxidant sources were studied on minimizing autoxidation of sesame oil. Mangosteen peel contains high levels of xanthones as $\alpha$-mangostin and $\gamma$-mangostin which are known to possess strong antioxidant activity. Cinnamon contains high amount of polyphenols and proanthocyanidins and the extract is able to reduce lipid peroxidation in $\beta$ carotene - linoleic acid system and it has a protective capacity against irradiation induced lipid peroxidation in liposomes (Mancini-Filho and Van-Koiij, 1998). Chilli is a rich source of vitamin C and contains compounds like capsaicin, capsanthin and capsorubin. It has been found that the capsanthin suppressed hydroperoxide formation and the radical scavenging effect of capsanthin was found to last longer (Pandey et al., 2012).

\section{Materials and Methods}

\section{Materials}

Sesame oil was obtained from local market in Sri Lanka. All the chemicals used in this study were of analytical grade with highest purity available (>99.5\%) and obtained from Sigma Chemicals Company (MO, USA).

\section{Preparation of plant extracts}

\section{Mangosteen peel extract}

Mangostin peels were removed and chopped into small pieces an dried for about two days in a dryer to remove moisture. Dried mangosteen peel pieces were ground and sieved through a sieve (500 gauge). A sample of (20 g) mangosteen peel powder was mixed with $30 \mathrm{~mL}$ of acetone and stirred for 30 minutes using mechanical stirrer. Then the solution was filtered using no.1 Whatman filter paper and the filtrate was collected into round bottom flask. The solvent was removed using Rotorvapor (Rotavapor R-3000, Switzerland) to obtain the extract.

\section{Cinnamon extract}

Cinnamon powder (20 g) was mixed with $30 \mathrm{~mL}$ of acetone and stirred for 30 minutes on a mechanical stirrer. Resulting solution was filtered through no.1 Whatman filter paper and filtrate was collected in a round bottom flask and extraction was done using Rotavapor. 
Chilli extract

Chili powder (20 g) was mixed with $30 \mathrm{~mL}$ of acetone and stirred for 30 minutes using a mechanical stirrer. Resulting solution was filtered through no.1 Whatman filter paper and filtrate was collected in a round bottom flask and extraction was done using Rotavapor.

\section{Sample preparation}

Sesame oil contained no added natural extracts was taken as control. For the test samples, oils were directly added with mangosteen peel, cinnamon and chili extracts each at concentration of $5 \mathrm{mg} / 100 \mathrm{mg}$ of oil before being subjected to oven test.

\section{Oven test}

Samples of each oil treatment (control, with mangosteen peel, with cinnamon, with chili) were placed in separate open glass vials $(5 \mathrm{~mL})$ and stores in oven maintained at $60 \pm 5{ }^{\circ} \mathrm{C}$ for up to $1,3,5,7,14,21$ and 28 days. Oil samples were analyzed immediately after each storage period. The temperature of $60 \pm 5{ }^{\circ} \mathrm{C}$ was used to stimulate storage in real condition.

\section{Chemical analysis}

PV was determined according to Damaso et al. (2001) and TBARS was determined by AOCS method (1998). Lipid oxidation product of CDs and CTs were determined by specific absorptivity values at 232 and $270 \mathrm{~nm}$ using UV spectrophotometer (UV 1601, Shimadzu, Japan) (Besbes et al., 2004). Specific absorptivity was calculated as follows;

$$
E=\frac{A}{C \times l}
$$

Where, $\mathrm{E}$ is the specific absorptivity, $\mathrm{A}$ is the absorbance measured at either $232 \mathrm{~nm}$ (for CDs) or $270 \mathrm{~nm}$ (for $\mathrm{CTs}$ ), $\mathrm{C}$ is the concentration of the oil in $\mathrm{g} / 100 \mathrm{~mL}$ and 1 represents the path length of the cuvette in $\mathrm{cm}$ (Pegg, 2005).

\section{Statistical analysis}

The data were analyzed using Minitab 16. All measurements were performed in triplicate. The ANOVA tables were constructed using GLM procedure. Duncan's new multiple range test was used to determine significant differences at 0.05 significant levels.

\section{Results and Discussion}

The figures 1, 2, 3 and 4 shows the variation of PV, TBARS, CD and CT values of oils added with different extracts up to 28 days of storage. The percent increment of PV, TBARS, CD and CT are shown in Table 1. According to figure 1, the PV of the all samples increased gradually during storage. The percentage increment of PV of control was lesser than the samples added with either cinnamon or chilli extract. There was no significant difference between the percent increment of PV between control sample and sample added with mangosteen peel extract. Among extracts tested, sample with mangosteen peel extract showed the least percent increment $(2.76 \%)$ which indicate highest oxidative stability of the sample. 
Umani Walallawita et al / The Effect of Mangosteen (Garcinia mangostana), Cinnamon .....

Table 1: Percentage increment of PV, TBARS, CD and CT of different plant extracts

\begin{tabular}{lllll}
\hline Extract & PV $(\%)$ & TBARS $(\%)$ & CD $(\%)$ & CT $(\%)$ \\
\hline Mangosteen peel & $2.76 \mathrm{~b}$ & $0.12 \mathrm{~d}$ & $0.84 \mathrm{c}$ & $1.14 \mathrm{c}$ \\
\hline Cinnamon & $3.18 \mathrm{a}$ & $1.36 \mathrm{c}$ & $1.45 \mathrm{~b}$ & $1.97 \mathrm{a}$ \\
\hline Chili & $3.33 \mathrm{a}$ & $2.70 \mathrm{~b}$ & $1.89 \mathrm{~b}$ & $1.42 \mathrm{~b}$ \\
\hline Control & $2.99 \mathrm{~b}$ & $10.32 \mathrm{a}$ & $3.59 \mathrm{a}$ & $1.41 \mathrm{~b}$ \\
\hline
\end{tabular}

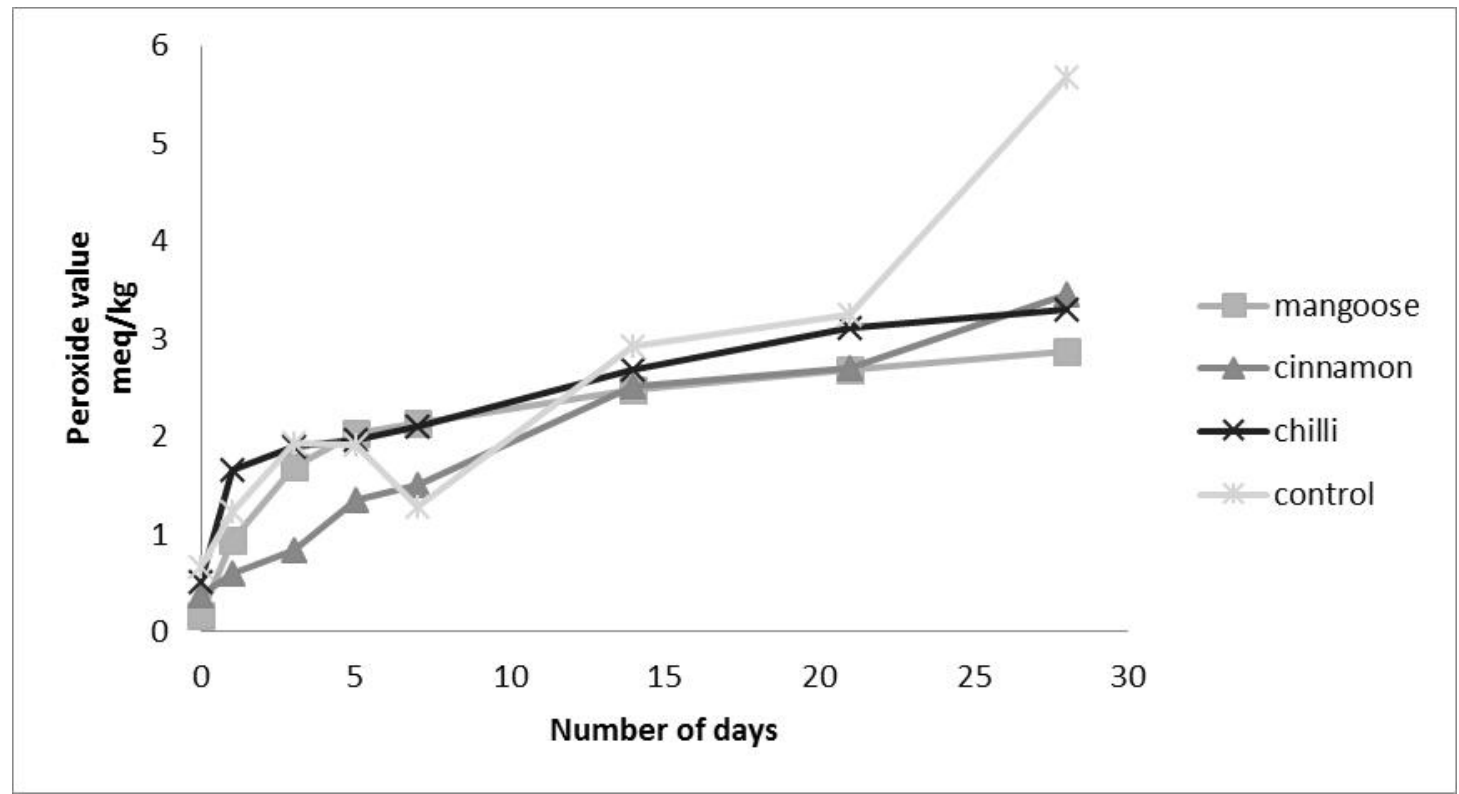

Figure 1: Variation of PV of oils added with different extracts during the storage period

TBARS is the most widely used test for measuring the extent of lipid peroxidation. The basic principle of the method is the reaction of one molecule of malonaldehyde and two molecules of TBA to form a red malonaldehyde-TBA complex, which can be quantitated spectrophotometrically at $532 \mathrm{~nm}$. According to figure 2 , the TBARS values increased continuously over the storage period while the oil added with mangosteen peel extract showed less value than others. The least percent increment $(0.12 \%)$ of TBARS was shown by sesame oil which contained mangosteen peel extract followed by sample with cinnamon extract $(1.36 \%)$ and sample with chilli extract (2.70). 


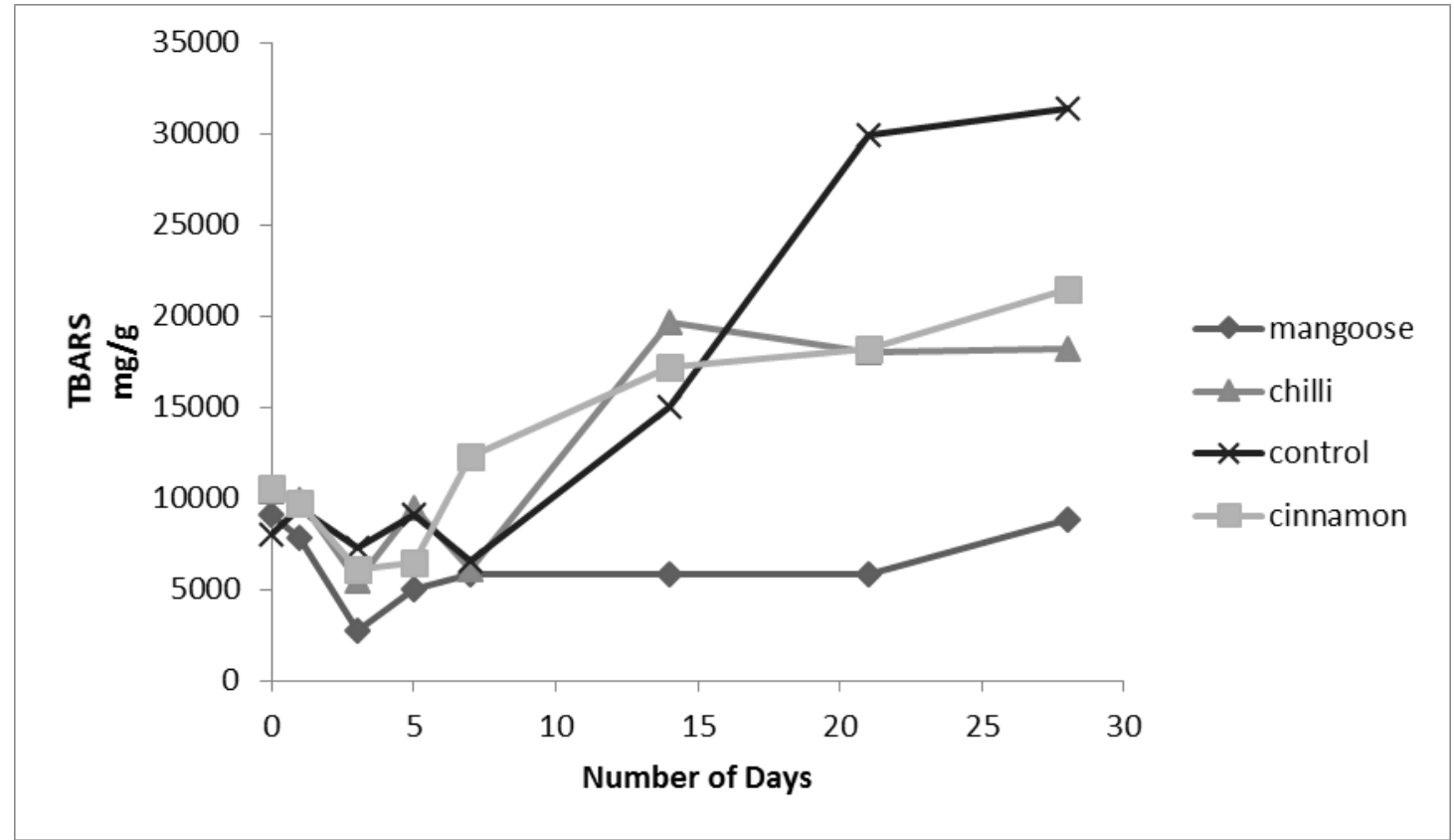

Figure 3: Variation of TBARS of oils added different extracts during the storage period

The formation of peroxides is concurrent with conjugation of double bonds in polyunsaturated fatty acids, which can be measured using the specific absorptivity of CDs and CTs at 232 and $270 \mathrm{~nm}$ in the UV spectrum. All sesame oil samples revealed the increase of specific absorptivity values of CDs and CTs with time (Figure 3 and 4). The addition of natural plant extracts lowered these values. Among the extracts tested, sample with mangosteen peel showed the least percent increment of CD $(0.84 \%)$ and CT $(1.14 \%)$.

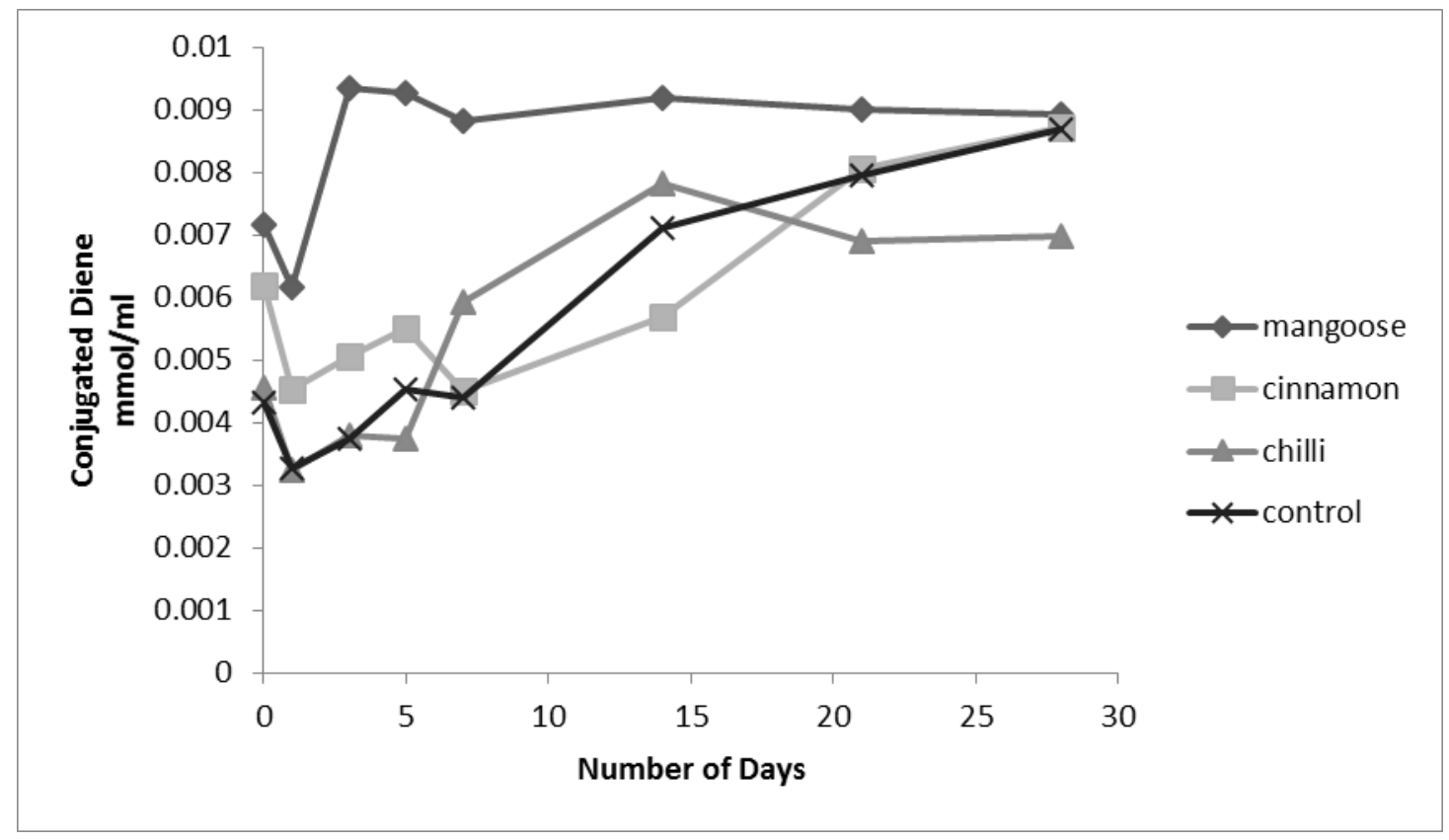

Figure 2: Variation of CD of oils added different extracts during the storage period 


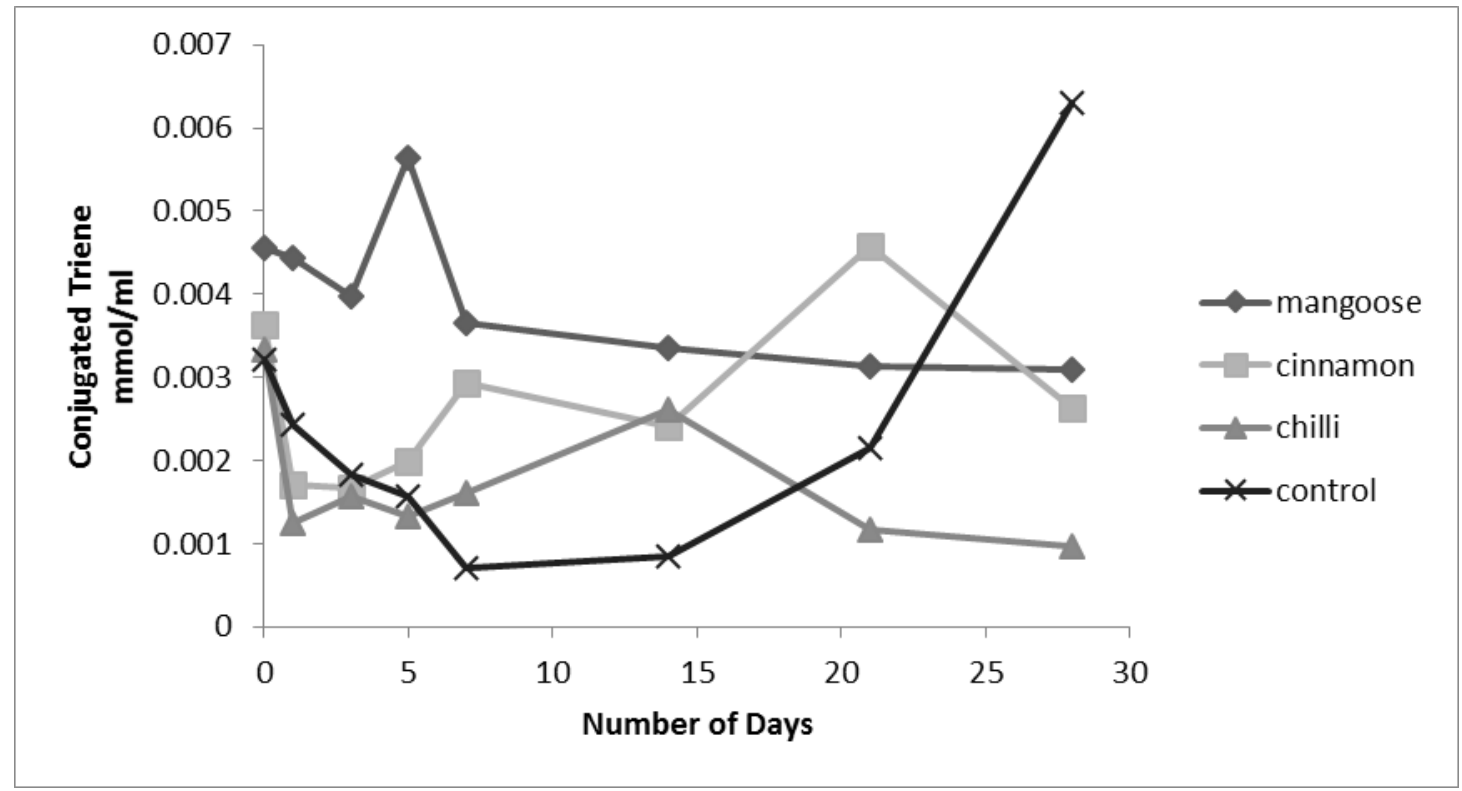

Figure 4: Variation of CT of oils added different extracts during the storage period

Even though all plant extracts tested in this study showed significant effect in minimizing the oxidation of sesame oil, antioxidant effect of mangosteen peel extract was higher than cinnamon and chilli extracts. Oil samples with mangosteen peel extract showed the minimum difference between final and initial PV, TBARS, $\mathrm{CD}$ and CT values which indicate lowest oxidation of the oil. Some other researchers also have reported the antioxidant property of mangosteen peel extract (Yoshikawa et al., 1994; Okonogi et al., 2007; Palakawong et al., 2010) however the extraction method could have effect on extent of activity (Palakawong et al., 2010). Mangosteen peel contains antioxidant namely xanthones which is capable of reducing oxidation. There are over 200 xanthones that can be found in nature, but mangosteen is reported to contain over 50 kinds of xanthones (Pedraza-Chaverri et al., 2008). Chilli and cinnamon extracts also showed antioxidant activity to some extent, but less than mangosteen peel extract. Chilli contains phenolic compounds such as capsaicin and cinnamon contains cathechin and epicatechin which have contributed to antioxidant activity but not effective as xanthones in mangosteen peel extract.

\section{Conclusion}

Based on the findings of this study, it can be concluded that mangosteen peel extract possess higher antioxidant effect than chilli and cinnamon extracts against oxidation of sesame oil and thus addition of mangosteen peel extract to sesame oil will reduce the rate of autoxidation. Since mangoosteen peel is a waste material, it could be effectively utilized to increase the oxidative stability of plant oils.

\section{References}

AOCS, 1998, American Oil Chemists' Society. Official method Cd 19-90. 2-Thiobarbituric acid value. Direct method. In: Firestone D, editor. Official Methods and Recommended Practices of the American Oil Chemists' Society, 5th ed. (Champaign), pp. 3.

Besbes, S., Blecker, C., Deroanne, C., Lognay, G., Drira, N.E., Attia, H., 2004, Quality characteristics and oxidative stability of date seed oil during storage. Food Science and Technology International, 10, 333-338.

Choe, E., Min, D.B., 2006, Mechanisms and factors for edible oils oxidation. Comprehensive Reviewes in Food Science and Food Safety, 5, 169-186. 
Damaso, H., Antonio, P.G., Isabel, M.M.M., 2001, A Rapid Spectrophotometric Method for the Determination of Peroxide Value in Food Lipids with High Carotenoid Content. Journal of American Oil Chemists' Society, 78(11), 1151-1155.

Kamal-Eldin, A., Appelqvist, L., 1995, The effects of extraction methods on sesame oil stability. Journal of American Oil Chemists' Society, 72(8), 967-969.

Mancini-Filho, J., Van-Koiij, A., 1998, Antioxidant activity of cinnamon (Cinnamomum Zeylanicum, Breyne) extracts. Bollettino Chimico Farmaceutico, 137(11), 443-447.

Okonogi, S., Duangrat, C., Anuchpreeda, S., Tachakittirungrod, S., Chowwanapoonpohn, S., 2007, Comparison of antioxidant capacities and cytotoxicities of certain fruit peels. Food Chemistry, 103, 839-846.

Palakawong, C., Sophanodora, P., Pisuchpen, S., Phongpaichit, S., 2010, Antioxidant and antimicrobial activities of crude extracts from mangosteen (Garcinia mangostana L.) parts and some essential oils. International Food Research Journal, 17, 583-589.

Pandey, S.K., Yadav, S.K., Singh, V.K., 2012, A overview on Capsicum annum L. Journal of Pharmaceutical Science and Technology, 4(2), $821-828$.

Pedraza-Chaverri, J., Cárdenas-Rodríguez, N., Orozco-Ibarra, M., Pérez-Rojas, J.M., 2008, Medicinal properties of mangosteen (Garcinia mangostana). Food and Chemical Toxicology, 46, 3227-3239.

Pegg, R., 2005, Lipid oxidation stability. In: Wrolstad RE, Acree TE, Decker EA, Penner MH, Reid DS, Schwartz SJ, Shoemaker CF, Smith D, Sporns P, editors, Handbook of Food Analytical Chemistry: Water, Proteins, Enzjmes, Lipids, and Carbohydrates, (Canada: John Wiley \& Sons, Inc.), pp. 513 - 547.

Suttirak, W., Manurakchinakorn, S., 2014, In Vitro antioxidant properties of mangosteen peel extract. Journal of Food Science and Technology, 51(12), 3546-3558.

Yoshikawa, M., Harada, E., Miki, A., Tsukamoto, K., Liang, S.Q., Yamahara, J, Murakami, N., 1994, Antioxidant constituents from the fruit hulls of mangosteen (Garcinia mangostana L.) originating in Vietnam. Yakugaku Zasshi, 114(2), 129-133. 